\title{
Is male circumcision an “Invisible Condom?" Men's Knowledge, Attitudes, Perception of Risk to HIV infection and willingness to circumcise in Harare, Zimbabwe
}

\section{Kudzaishe Mangombe ${ }^{1}$, Acheampong Yaw Amoateng and Ishmael Kalule-Sabiti}

School of Research \& Postgraduate Studies, North-West University (Mafikeng Campus), South Africa

\begin{abstract}
In 2009, the Zimbabwe Ministry of Health launched a national voluntary medical male circumcision programme, targeting to circumcise $80 \%$ of males by 2015 . The present study examines the impact of men's knowledge, attitudes and perception of risk of HIV infection to their willingness to accept circumcision. A cross-sectional survey was conducted on 666 men aged 15-35 in Harare, Zimbabwe. The present study employed descriptive statistics, bivariate and logit regression model. The results showed that men who had favourable attitudes towards male circumcision and those who perceived themselves to be at a higher risk of HIV infection were more likely to be willing to circumcise. Contrary to expectation, knowledge of male circumcision was not significantly related to willingness to circumcise. The study's findings highlight the need for the promotion of the kind of health education which would emphasise the health benefits of male circumcision.
\end{abstract}

Keywords: Perception of risk, HIV prevention

\section{Résumé}

Cette étude employé le modèle de régression logistique pour examiner l'impact des hommes connaissances, attitudes et perception du risque d'infection par le $\mathrm{VIH}$ sur leur volonté de circoncire à Harare, au Zimbabwe. Les résultats ont montré que les hommes qui avaient des attitudes favorables à la circoncision masculine et ceux qui percevaient eux-mêmes pour être un risque plus élevé d'infection à $\mathrm{VIH}$ étaient plus susceptibles d'être disposés à circoncire. Contrairement aux attentes, connaissances de la circoncision masculine n'était pas significativement reliée à volonté pour circoncire. En outre, l'éducation a été trouvée inversement lié à la volonté de circoncire comme hommes avec l'enseignement primaire étaient plus susceptibles d'être disposé à circoncire par

\footnotetext{
${ }^{1}$ Corresponding Author: kmangombe@yahoo.com
} 
rapport aux hommes avec des niveaux plus élevés de l'éducation. Résultats de l'étude soulignent la nécessité pour la promotion du genre d'éducation à la santé qui insiste sur les bienfaits de la circoncision masculine.

Mots-clés: Perception du risque, la circoncision masculine, la connaissance, Zimbabwe

\section{Introduction}

In Zimbabwe, traditional male circumcision has been performed by a few ethnic groups since time immemorial, albeit, on a very small scale and as a mark of cultural identity (MOHCW, 2009). Following the success of the random clinical trials and the endorsement of the procedure by the World Health Organisation and the mounting empirical evidence that male circumcision can partially prevent the transmission and acquisition of HIV/AIDS and reducing certain types of cancers (Drain, Halperin, Hughes, Klausner, \& Bailey, 2006; Gray et al., 2009; Tobian, Gray, \& Quinn, 20I0; WHO/UNAIDS, 20II), the Zimbabwean government has integrated it into the country's health care system as a way of curbing the spread of HIV/AIDS.

Following the official integration of male circumcision into the country's health care system, the government sought to circumcise $80 \%$ of men aged between I549 years by 2015 (MOHCW, 2009). Yet, by 2013 only $10.6 \%$ of the national target had been met (WHO, 20l4). The slow uptake of circumcision in Zimbabwe is rather unfortunate because it has been estimated that reaching the national target of 80 percent circumcision rate could have prevented $42 \%$ of the new HIV/AIDS infections between $20 \mathrm{II}$ and 2025
(Njeuhmeli et al. 20I I). As a result of the low and slow uptake of circumcision in Zimbabwe, coupled with the fact that Zimbabwe is mainly a non-circumcising society, one wonders what factors contribute to this state of affairs. Questions that arise from this state of affair are whether there is enough knowledge of male circumcision procedure and its health benefits in the country? Besides the adequacy of knowledge of the procedure, what attitudes do people have towards the procedure?

As far as knowledge of male circumcision and attitudes towards the procedure are concerned, Mavhu et al. (20II) examined the effect of knowledge and attitudes towards male circumcision and whether men were willing to undergo the procedure in rural Zimbabwe. In their study, Mavhu et al. found that knowledge about male circumcision was low although attitudes were favourable. However, their study did not control for the effect of perception of risk to HIV infection. Studies focusing on risk perception and the willingness to circumcise are scarce in Zimbabwe. Also, Chikutsa \& Maharaj (20I5) found that even though participants were knowledgeable about male circumcision, less than half of them expressed willingness to circumcise. 


\section{The Present Study}

It is against the backdrop of the low and slow uptake of circumcision in Zimbabwe and the relative absence of empirical studies examining the reasons for this situation that we undertake the present study. Even though as indicated above, there has been some effort to understand why the uptake of the procedure is low and slow, there is a gap in the existing knowledge base. For instance although both Mavhu et al (20II) and Chikutsa \& Maharaj (2015) examined the effect of knowledge of the procedure on men's willingness to circumcise, they did not look at the possible effect perception of risk to HIV/AIDS by the participants in their studies.

It is the aim of the current study, therefore, to add to the existing literature on male circumcision by examining the impact of knowledge, attitudes and perception of risk with regard to HIV/AIDS on the willingness of men in Harare, Zimbabwe, to accept circumcision. The study uses cross-sectional quantitative data collected between May and July 2014 to answer its central research question: To what extent do men's knowledge, attitudes and perception of risk of HIV impact on their willingness to circumcise? To answer this central research question, we also control for the effects of such background characteristics as age, education, ethnicity, religion, marital status and employment status, ever heard of Voluntary Medical Male Circumcision (VMMC), ever tested for HIV and approval of Voluntary Counselling and Testing (VCT) prior circumcision.

\section{Literature Review}

As far as male circumcision is concerned, many existing studies have documented evidence that knowledge of issues regarding the practice affects men's willingness to circumcise. For example, it was found that in rural Kwazulu-Natal in South Africa men with little knowledge about the health benefits of male circumcision were the least willing to accept circumcision (Scott, Weiss, \& Viljoen, 2005). In Tanzania, participants in a focus group discussion were able to define circumcision and mentioned that male circumcision may prevent HIV and STIs, increased virility, sexual pleasure and hygiene. They expressed interest in being circumcised (Plotkin et al., 20 I 3; Tarimo et al., 20I2). However, studies in Zimbabwe found that participants were knowledgeable about male circumcision but less than half of the male participants expressed willingness to circumcise (Chikutsa \& Maharaj, 20I5).

Other studies revealed that acceptability of male circumcision was not always a reflection that respondents have knowledge about male circumcision (Khumalo-Sakutukwa et al., 2013; Mavhu et al., 20 I I). In addition, some studies have shown that respondents were not aware that male circumcision was an HIV prevention strategy and they believed that circumcised men were at risk of contracting the virus (Brito, Luna, \& Bailey, 2010). Such beliefs underscore the scepticism surrounding male circumcision. In this study, we expected respondents who are knowledgeable about male circumcision to be more willing to accept circumcision than those without any knowledge about the practice. One's 
personal perception of risk determines one's willingness to adopt a health seeking behaviour. In fact, several studies have established that perception of risk to HIV infection is a predisposition for willingness to accept circumcision (Keetile \& Rakgoasi, 20I4; Macintyre et al., 20I4). In all these studies, men who professed themselves to be at low risk to HIV/AIDS were less inclined to be circumcised. In the present study, we expected that individuals who perceived themselves not to be at risk of HIV infection would not be willing to be circumcised compared to those who perceive themselves to be at high risk of the disease.

Attitudes towards male circumcision can significantly influence the willingness to be circumcised in previously noncircumcising communities. Negative attitudes can exist from the fear of pain, surgical complications and perceived threats to masculinity (Plotkin et al., 20I3). Also, studies done in Kenya and Malawi have shown that participants who had a positive attitude towards male circumcision were willing to be circumcised (Mattson, Bailey, Muga, Poulussen, \& Onyango, 2005; Ngalande, Levy, Kapondo, \& Bailey, 2006).

Regional differences in the prevalence of male circumcision have been attributed to differences in attitudes towards male circumcision in Malawi (Dionne \& Poulin, 20I3). In some studies, respondents who had positive attitudes towards male circumcision were willing to circumcise to avert Sexually Transmitted Infections (STIs), including HIV and to improve hygiene (Gasasira et al., 20I2). In the present study, we expected respondents with favourable attitude to circumcision to be more willing to be circumcised than those with unfavourable attitude.

The Theoretical and Conceptual Framework

Health promotion programmes have been designed on condition that information about causes of diseases will promote health seeking behaviours. Health seeking behaviour is preceded by complex decision making processes that can be governed by individual knowledge of, attitudes and perception of risk to a disease. The present study is guided by the Health Belief Model (HBM). The HBM is a psychological model that endeavours to elucidate and predict behaviours by focusing on the individual's sociodemographic characteristics, attitudes, beliefs and perceptions (Rosenstock, Strecher, \& Becker, 1994). In this context, the HBM provides a framework to explain why some are willing to accept circumcision to minimise HIV infection, while others are not willing to be circumcised.

The HBM assumes that decisionmaking is purely an individual decision with regard to health intervention procedures. For instance, the HBM would help predict that individuals would be circumcised to prevent HIV and certain cancers. Individuals would be willing to circumcise if they perceived the problems to be health threatening and only if they perceived that the benefits from male circumcision are greater than the threats (barriers). So, the HBM explains the probability that individuals will involve themselves in particular desirable health activity depending on how related it is to one's 
belief about the severity of the potential illness.

\section{Data and Methods}

\section{Sampling design and Procedure}

The present study uses data from a crosssectional survey of males in Harare, Zimbabwe. Using the 2012 Zimbabwean census (Zimbabwe National Statistics Agency, 20I2) as a sampling frame, a multistage sampling design, involving three stages, was employed. The first stage involved the selection of Primary Sampling Units (PSUs) which were the Enumeration Areas (EAs). The second stage involved the selection of households as Secondary Sampling Units (SSUs). The third stage involved the serial selection of individuals aged I5-35 years old within households in the Enumeration Areas (EAs) ${ }^{2}$.

A total of 853 men were selected for the interview, but 69 of them refused to participate, leaving 784 respondents. Circumcision status was ascertained by two strategies: First, we asked respondents a universal question: "Are you circumcised?" Second, we showed them sample pictures of circumcised and uncircumcised penises to reduce instances of misclassification of a circumcision status. A total of 118 men reported being circumcised, but the analysis is restricted

\footnotetext{
${ }^{2}$ The household enumeration ensured that all household members who were aged 15-35 were identified and given an equal chance to
}

to the 666 that reported to be uncircumcised. All interviews were conducted in either Shona or English by male interviewers because of the all-male nature of the subject.

\section{Measures}

\section{Dependent variable}

Our dependent variable, willingness to circumcise, was measured by one closedended item: "Some men are circumcised, that is, the foreskin is completely removed from the penis. "Are you willing to be circumcised?" The responses were (I) "Yes" and (2) "No".

Independent variables (main explanatory variables)

Knowledge about male circumcision

Knowledge about male circumcision was measured by 10 items measured at the nominal level. The responses for each item were coded 0 and I, with 0 indicating that an individual does not have knowledge about that particular question and I indicating that an individual had knowledge about the particular question. A knowledge score was computed by summing up the individual knowledge questions. The minimum knowledge score was 0 and maximum score was 10 . The sample questions include: participate in the survey. An eligible participant was one de facto male household member aged between 15-35 years. 
(I)What do you understand by the term male circumcision?

(2) Is circumcision as good as an 'invisible condom' in preventing HIV transmission?

(3) Does male circumcision reduce the chances of transmitting HIV

(4) Does Male circumcision reduce penile cancer?

(5)Are Circumcised men still recommended to use condoms?

(6) Does male circumcision improve penile hygiene?

(7) Can male circumcision alone prevent HIV contraction?

(8) Can an HIV negative woman contract HIV/STI after having unprotected sex with a HIV positive circumcised man?

(9) Can an HIV negative circumcised man contract HIV/STI after having unprotected sex with a HIV positive woman?

(I0) How long should a circumcised man abstain from sexual intercourse?

\section{Attitudes towards Male Circumcision}

Attitude towards circumcision was measured using five statements measured on a 5-point Likert scale. Sample statements include the following:

(I) An HIV infected man should be circumcised;

(2) Promoting male circumcision is good for health;

(3) It is easier to keep clean if circumcised;

(4) Uncircumcised men are more likely to contract HIV;

(5) Promoting male circumcision would cause an increase in risky sexual behaviour.

The responses to the attitudes statements ranged from (I) 'Strongly disagree', (2) 'Disagree', (3) 'Neutral', (4) 'Agree' and (5) 'Strongly agree'. Some items were reverse coded if they were undimensional for the purposes of statistical analyses. The Cronbach's alpha for this 5- item scale was 0.60 . An additive scale was computed by summing up the responses to the five statements. The total score was 20 and mean score was I5.53.

\section{Perception of risk to HIV infection}

Perception of risk to HIV infection was measured as an ordinal variable. Respondents were asked the following question: "Do you think you are at risk of contracting HIV infection". The responses were (I) "Yes at higher risk", (2) "Yes at low risk" and (3) "Not at risk at all.

\section{Independent variables}

Age was measured as a nominal-level variable as follows: 15-19, 20-24, 25-30 and 30-35 years; marital status was measured as: never married, formerly married and married/living together; education was measured as: primary, secondary and higher; wealth status was measured as: low, medium and high. Employment status was categorised into unemployed and employed; religion was 
measured as Mainline (Catholics and Protestants combined into one category Tarusarira \& Ganiel (20I2), Apostolic sect, Pentecostal, Other Religion and No Religion; ethnicity was categorised into Shona and Other, ever tested for HIV was categorised into I="Yes" and 2 ="No". Finally, approve of Voluntary Counselling and Testing (VCT) prior to circumcision was categorised into I="Yes" and $2=$ "No".

The analysis of the data was done at the univariate, bivariate and multivariate levels respectively. For the univariate analysis, descriptive statistics were used, while for the bivariate analysis, the Chi-Square Tests of Independence were employed to examine the relationships amongst pairs of variables. Finally, for the multivariate analysis, two logit regression models were used. The first model involved examining the effects of the three main independent variables, namely, knowledge of male circumcision, attitudes towards male circumcision, and perception of risk to HIV infection, and willingness to circumcise. Second model involved the three main independent variables after the effect of the other independent variables had been taken into account.

\section{Results}

\section{Sample characteristics}

Table I shows the distribution (in percentages) of the background sociodemographic characteristics of the respondents in the sample. Slightly more than two-fifths (40.8\%) of the respondents are willing to circumcise. Almost one-third (29.4\%) of the respondents are 20-24 years old, while more than a fifth $(21.5 \%)$ of the respondents are aged 30-35 years old.

In terms of marital status, almost twothirds $(63.8 \%)$ of the respondents are never married, while most of the respondents have only a secondary level of educational attainment (79.1\%). $61.0 \%$ of the respondents have never been tested for HIV and $91.3 \%$ belong to the Shona ethnic group. Over three-quarters (76.4\%) of the respondents do not approve of voluntary counselling and testing before circumcision, while only one percent $(I .1 \%)$ have never heard of VMMC. 
Table I: Socio-demographic characteristics of the respondents $(n=666)$

\begin{tabular}{|c|c|c|}
\hline Variable & Frequency & Percent \\
\hline \multicolumn{3}{|l|}{ Age group } \\
\hline $15-19$ & 152 & 22.9 \\
\hline $20-24$ & 195 & 29.4 \\
\hline $25-29$ & 174 & 26.2 \\
\hline $30-35$ & 143 & 21.5 \\
\hline \multicolumn{3}{|l|}{ Marital status } \\
\hline Married/Living together & 221 & 33.2 \\
\hline Formerly Married & 20 & 3.0 \\
\hline Never Married & 425 & 63.8 \\
\hline \multicolumn{3}{|l|}{ Education } \\
\hline Primary & 32 & 4.8 \\
\hline Secondary & 527 & 79.1 \\
\hline Higher & 106 & 16.1 \\
\hline \multicolumn{3}{|l|}{ Wealth status } \\
\hline Low & 234 & 35.1 \\
\hline Medium & 216 & 32.4 \\
\hline Higher & 216 & 32.4 \\
\hline \multicolumn{3}{|l|}{ Employment status } \\
\hline Employed & 380 & 57.1 \\
\hline Unemployed & 286 & 42.9 \\
\hline \multicolumn{3}{|l|}{ Religion } \\
\hline Mainline & 228 & 34.2 \\
\hline Pentecostal & 160 & 24.0 \\
\hline Apostolic Sect & 147 & 22.1 \\
\hline Other Religion & 65 & 9.8 \\
\hline No religion & 66 & 9.9 \\
\hline \multicolumn{3}{|l|}{ Ethnic group } \\
\hline Shona & 608 & 91.0 \\
\hline Other & 58 & 39.0 \\
\hline \multicolumn{3}{|l|}{ Ever tested for HIV } \\
\hline Yes & 406 & 61.0 \\
\hline No & 260 & 39.0 \\
\hline \multicolumn{3}{|c|}{ Approval of VCT prior circumcision } \\
\hline Yes & 157 & 23.6 \\
\hline No & 509 & 76.4 \\
\hline \multicolumn{3}{|l|}{ Ever heard of VMMC } \\
\hline Yes & 659 & 98.9 \\
\hline No & 7 & 1.1 \\
\hline \multicolumn{3}{|l|}{ Willingness to circumcise } \\
\hline Yes & 272 & 40.8 \\
\hline No & 394 & 59.2 \\
\hline Total & 666 & 100 \\
\hline
\end{tabular}


Bivariate analysis

Independent characteristics willingness to circumcise

Table 2 presents the relationship between the independent variables (knowledge about male circumcision, attitudes towards male circumcision and perception of risk to HIV infection) and willingness to circumcise. Mean knowledge score is highest among men who are willing to circumcise (mean 7.74/SD, I.59)

by compared to men who are not willing (mean, 7.72/SD, I.59). Favourable attitudes are highest among men who are willing to circumcise (mean, 16.79/SD, 2.33) compared to men who are not (mean, I4.6I/SD, 3.23). Perception of risk to HIV infection is not related to willingness to circumcise.

Table 2 : Independent characteristics by willingness to circumcise

\begin{tabular}{llll} 
Variable & Yes & No & \\
\hline $\begin{array}{l}\text { Continuous variables } \\
\text { Knowledge }\end{array}$ & M(S.D) & M(SD) & \\
Attitudes & $7.74(I .59)$ & $7.72(1.59)$ & \\
& $16.79(2.33)$ & $14.6 I(3.23)$ & Total \\
Categorical variables & & & 0.191 \\
Perception of risk to HIV & Percent & Percent & 362 \\
No risk & & Chi-square & 235 \\
Low risk & 38.0 & 62.0 & 68 \\
High risk & 43.0 & 57.0 & 51.5 \\
\hline
\end{tabular}

Percent distribution of socio- men with secondary and higher education demographic characteristics by respectively. Religious affiliation is strongly willingness to circumcise

Table 3 shows the relationships between the socio-demographic characteristics and willingness to be circumcised using the Chi-Square tests of independence. Contrary to our expectation, education is inversely associated with willingness to circumcise; $56.3 \%$ of the men with primary education report willingness to circumcise compared to $42 \%$ and $30 \%$ of associated with willingness to circumcise among men. Table 3 shows that $56.1 \%$ of men with no religious affiliation reported willingness to circumcise compared to only $37 \%$ of other Christians. Further, almost a third (32.7\%) of Pentecostal Christians reported willingness to circumcise compared to $42 \%$ of Mainline Christians and Apostolic Sect Christians respectively. 
African Population Studies Vol. 29, No. 2, Supplement, 2015

Table 3: Socio-demographic characteristics by willingness to circumcise $(n=666)$

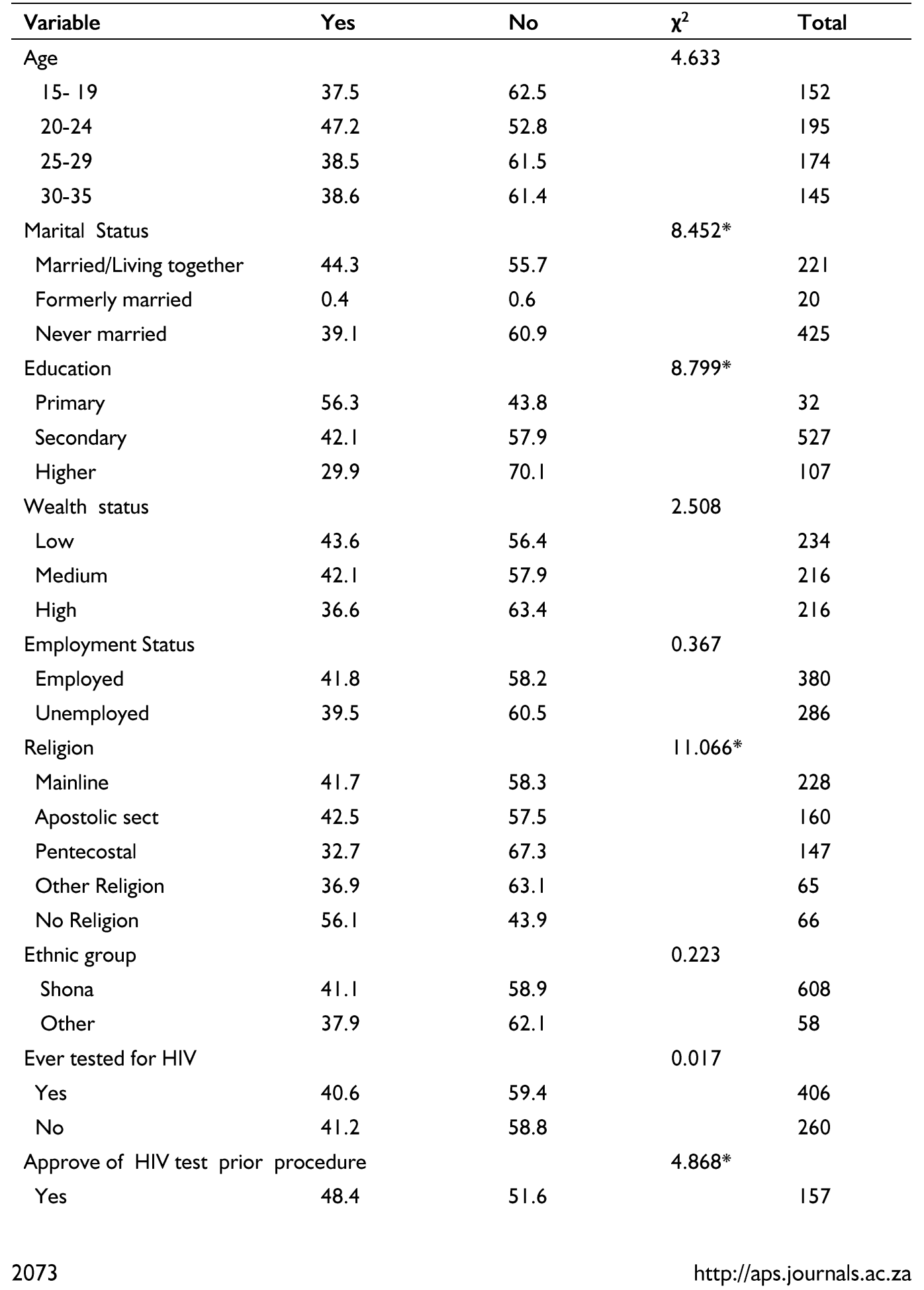


African Population Studies Vol. 29, No. 2, Supplement, 2015

\begin{tabular}{lllll}
\hline Variable & Yes & No & $\chi^{2}$ & Total \\
\hline No & 38.5 & 61.5 & & 509 \\
Ever heard of VMMC & & & 0.000 & \\
Yes & 40.8 & 59.2 & & 644 \\
No & 40.9 & 59.1 & & 022 \\
\hline Total & 272 & 394 & & 666 \\
Percent & 40.8 & 59.2 & & 100 \\
\hline
\end{tabular}

${ }^{+} \mathrm{p}<.1,{ }^{*} \mathrm{p}<.05,{ }^{*} \mathrm{p}<.01$

\section{Multivariate analysis}

Table 4 shows the results of logistic regression analyses depicting the two models predicting men's willingness to circumcise. The first Model (MI) examines the effect of the independent variables (knowledge about male circumcision, attitudes towards male circumcision and perception of risk to HIV infection) on willingness to circumcise.

The second (M2) examines the effect of the independent variables controlling for socio-demographic characteristics. Model I on Table 4 shows that without the sociodemographic characteristics, only attitude towards male circumcision is significantly related to willingness to circumcise. Specifically, the table shows that men who have favourable attitudes towards male circumcision are $33 \%$ less likely to report willingness to circumcise. However, after controlling for other socio-demographic factors as shown in Model 2, the relationship between attitudes towards male circumcision and willingness to circumcise becomes positive.

In other words, men who have favourable attitudes towards male circumcision are more likely to report willingness to circumcise, while men who perceive themselves to be at high risk of HIV infection are 1.654 times more likely to be willing to circumcise compared to those who perceive themselves to be at no risk of HIV infection. With regards to education, there is a negative relationship between education and willingness to circumcise. Specifically, primary level educational attainment increases the odds of willingness to circumcise by $151 \%$ compared to those with higher educational attainment. Similarly, there is an inverse relationship between age and willingness to circumcise.

In terms of the effect of age, there is an inverse relationship between age and willingness to circumcise. For example, men aged 20-24 years old are 1.704 times more likely to report willingness to circumcise compared to those aged 30-35 years old. Finally, Table 5 shows that belonging to an Apostolic Sect decreases the odds of willingness to circumcise by $63 \%$ compared to membership of any religious faith, while membership of Other Christian faiths decreases the odds of circumcision by $51 \%$. 
Table 4. Logistic regression showing the predictors of willingness to be circumcised among men aged I5-35 in Harare, Zimbabwe.

\begin{tabular}{|c|c|c|c|c|c|c|}
\hline \multirow[b]{2}{*}{ Variable } & \multicolumn{3}{|c|}{ Model I } & \multicolumn{3}{|c|}{ Model 2} \\
\hline & B & S.E. & $\operatorname{Exp}(B)$ & B & S.E. & $\operatorname{Exp}(B)$ \\
\hline Knowledge score & -0.055 & $(0.053)$ & 0.946 & 0.081 & $(0.058)$ & 1.085 \\
\hline Attitude score & -0.257 & $(0.031)$ & $0.773 * *$ & 0.251 & $(0.032)$ & $1.286 * *$ \\
\hline \multicolumn{7}{|l|}{ HIV risk perception } \\
\hline \multicolumn{7}{|l|}{ No Not at risk at all (R) } \\
\hline Yes at higher risk & -0.382 & $(0.282)$ & 0.682 & 0.503 & $(0.299)$ & $1.654+$ \\
\hline Yes at low risk & -0.175 & $(0.182)$ & 0.840 & 0.177 & $(0.195)$ & 1.194 \\
\hline \multicolumn{7}{|l|}{ Age } \\
\hline \multicolumn{7}{|l|}{$30-35(R)$} \\
\hline $15-19$ & & & & 0.196 & $(0.365)$ & $1.216+$ \\
\hline $20-24$ & & & & 0.533 & $(0.298)$ & 1.704 \\
\hline $25-29$ & & & & 0.098 & $(0.267)$ & 1.103 \\
\hline \multicolumn{7}{|l|}{ Education } \\
\hline \multicolumn{7}{|l|}{ Higher (R) } \\
\hline Primary & & & & 0.918 & $(0.486)$ & $2.505^{+}$ \\
\hline Secondary & & & & 0.461 & 0.280 & 1.585 \\
\hline \multicolumn{7}{|l|}{ Marital status } \\
\hline \multicolumn{7}{|l|}{ Never married (R) } \\
\hline Married/living together & & & & 0.297 & $(0.255)$ & 1.346 \\
\hline Formerly married & & & & 0.049 & $(0.540)$ & 1.050 \\
\hline \multicolumn{7}{|l|}{ Wealth } \\
\hline \multicolumn{7}{|l|}{ High (R) } \\
\hline Low & & & & 0.102 & $(0.231)$ & 1.107 \\
\hline Medium & & & & 0.069 & $(0.222)$ & 1.071 \\
\hline \multicolumn{7}{|l|}{ Employment status } \\
\hline \multicolumn{7}{|l|}{ Unemployed (R) } \\
\hline Employed & & & & 0.142 & $(0.217)$ & 1.153 \\
\hline \multicolumn{7}{|l|}{ Religion } \\
\hline \multicolumn{7}{|l|}{ None (R) } \\
\hline Mainline & & & & -0.430 & $(0.318)$ & 0.650 \\
\hline Pentecostal & & & & -0.312 & $(0.335)$ & 0.732 \\
\hline Apostolic sect & & & & -0.993 & $(0.334)$ & $0.370 * *$ \\
\hline Other Religion & & & & -0.698 & $(0.395)$ & 0.498 \\
\hline \multicolumn{7}{|c|}{ Approve of VCT prior to MC } \\
\hline \multicolumn{7}{|l|}{ Disapprove (R) } \\
\hline Approve & & & & 0.274 & $(0.204)$ & 1.315 \\
\hline \multicolumn{7}{|l|}{ Ethnic group } \\
\hline Other $(\mathrm{R})$ & & & & & & \\
\hline
\end{tabular}




\begin{tabular}{|c|c|c|c|c|c|c|}
\hline \multirow[b]{2}{*}{ Variable } & \multicolumn{3}{|c|}{ Model I } & \multicolumn{3}{|c|}{ Model 2} \\
\hline & B & S.E. & $\operatorname{Exp}(B)$ & B & S.E. & $\operatorname{Exp}(B)$ \\
\hline Shona & & & & 0.013 & $(0.319)$ & 1.013 \\
\hline \multicolumn{7}{|l|}{ Ever tested for HIV } \\
\hline \multicolumn{7}{|l|}{ No $(R)$} \\
\hline Yes & & & & -0.049 & $(0.206)$ & 0.952 \\
\hline \multicolumn{7}{|l|}{ Ever heard of VMMC } \\
\hline \multicolumn{7}{|l|}{ No $(R)$} \\
\hline Yes & & & & -0.611 & $(0.500)$ & 0.543 \\
\hline Constant & 4.960 & 0.663 & 142.536 & -4.912 & 0.945 & 0.007 \\
\hline Observation & 666 & & & 666 & & \\
\hline Nagelkerke R Square & 0.164 & & & 0.210 & & \\
\hline $\mathrm{H}-\mathrm{L}$ gof test & 0.008 & & & 0.053 & & \\
\hline
\end{tabular}

${ }^{+} \mathrm{p}<.1,{ }^{*} \mathrm{p}<.05,{ }^{*} \mathrm{p}<.01$, Standard Errors in parenthesis ( )

\section{Discussion and conclusion}

The present study sought to contribute to the bourgeoning literature on male circumcision in Zimbabwe. While existing studies have examined the role of knowledge about male circumcision and attitudes towards circumcision on willingness to be circumcised, not much has been done to examine perception of risk to HIV infection. So, in addition to knowledge about male circumcision and attitudes towards male circumcision, the present study examined participants' perception of risk to HIV infection and controlled for several socioeconomic background characteristics of the participants.

The study found that having a favourable attitude towards male circumcision was positively associated with willingness to be circumcised. The findings about the role of attitudes towards circumcision and perception of risk to HIV infection on one hand and willingness to circumcise, on the other hand, are coherent with studies done in Kenya and Malawi (Mattson et al., 2005; Ngalande et al., 2006). For instance, there are several studies that found that HIV risk perception was an important predisposition in determining men's willingness to be circumcised (Hatzold et al., 20l4; Macintyre et al., 2014; Rosenstock et al., 1994). These two findings are theoretically grounded in the HBM in terms of how perceived benefits affect a person's behaviour; individuals who perceive themselves to be susceptible to HIV infection are more willing to take precautionary actions to mitigate the threat of contracting it.

Contrary to our expectation, education was negatively related to willingness to be circumcised in the present study. This finding about education in relation to willingness to circumcise is consistent with Asiimwe (20I I) who noted that men with primary education were more likely to be willing to circumcise compared to those with higher educational attainment. This finding about education's relationship with 
willingness to circumcise might appear counterintuitive because education is one of the coordinates of change in "traditional" societies. Yet, this effect of education could be reflecting education as a pattern maintenance variable as suggested by Parsons \& Shils (I95I) or what Abu-Lughod (196I) referred to as the "urban villagers". So, contrary to the notion that formal education is an agent of change, it could actually play the role of preserving the culture of a people. In fact, Collier (20I2) has observed that educated persons generally tend to be less receptive to new programmes perhaps because of the large amount of information at their disposal through their global connectedness. Moreover, we found that age was negatively associated with willingness to be circumcised, a finding which corroborates existing studies on the subject of male circumcision (Gasasira et al., 20I2; Macintyre et al., 20|4). Essentially, the finding reflects the relative ease with which young people adapt to change as a result of their malleability to peer pressure compared to the older generations (Gurman et al., 20 I5; Skolnik, Tsui, Ashengo, Kikaya \& Lukobo-Durrel, 20I4).

Religious doctrines play a pivotal role in shaping behaviour in general and the acceptance of certain health behaviours in particular. In fact, in Zimbabwe, some of the African Independent Churches have doctrines that are against conventional Western medicine and formal schooling (Chimininge, 20I4). In line with such doctrines, their members are totally prohibited from seeking western medical care, including male circumcision.
This attitude towards circumcision is a reflection of the general scepticism by all Christians in regard to male circumcision in view of the belief that the practice linked with the reduction of HIV and STIs infection. This is contrary to the Christian belief and teaching about abstinence and being faithful to one's partner as the only ways and means to prevent STIs. In fact, this perception by Christians is supported by previous findings which showed that Christians view and link male circumcision to promiscuous behaviour (Downs et al., 2013).

This study has shown that the willingness to circumcise in urban Zimbabwe is very low as less than half of the men in the sample $(40.8 \%)$ were willing to be circumcised. This proportion is much lower than the $52 \%$ estimated among rural men aged I 8-44 years Mavhu et al. (20l I). As male circumcision continues to spread in formerly noncircumcising countries, the impact of knowledge of male circumcision, attitudes towards male circumcision, perception of risk to HIV infection and willingness to circumcise requires continuous attention. The present study could be an indication that in a traditionally non-circumcising society like Zimbabwe, the decision for men to be circumcised may continue to be shaped by the socio-cultural context rather than education. As depicted by this study, knowledge about the procedure does not relate to willingness to circumcise. Health education messages that focus on the benefits of male circumcision are necessary to help create a demand for the procedure. Participants were aware of their level of perception of risk to HIV infection and were willing to circumcise. However, this 
perception of risk can be counterproductive, if people are not sensitised that male circumcision offer partial protection against HIV. Increased risk behaviour off set the gains of male circumcision.

\section{Limitation}

The study has two main limitations. First, the results of the study cannot be generalised to the general population of Zimbabwe because the sample came from only one out of 10 Provinces. Second, the information collected were self-reports from the participants and given the sensitivity of the issues covered by the survey the absolute objectivity of the responses could not be guaranteed despite assurances of anonymity and confidentiality.

\section{Ethical considerations}

Ethical clearance was granted by NorthWest University, South Africa and the Medical Research Council of Zimbabwe ( MRCZ/A/ 1848). We obtained a written informed consent from all study participants after describing the objectives of the study. The respondents were assured of confidentially and anonymity.

\section{Author Contributions}

Kudzaishe Mangombe conceived the study and led the data analysis and writing process. Acheampong Yaw Amoateng contributed substantially to the writing and reviewing of the paper. Ishmael KaluleSabiti reviewed the manuscript.

\section{References}

Abu-Lughod, J. (I96I). Migrant adjustment to city life: The Egyptian Case. American Journal of Sociology, 67(I), 22-32.

Brito, M. O., Luna, M., \& Bailey, R. C. $(20 \mid 0)$. The feasibility and acceptability of male circumcision among men, women, and health providers of the Altagracia Province, Dominican Republic. AIDS Care, 22(12), I530 1535.

http://doi.org/I0.1080/09540I2I.2010. 484455

Chikutsa, A., \& Maharaj, P. (20I5). Support for Voluntary Medical Male Circumcision (VMMC) for HIV Prevention among Men and Women in Zimbabwe. African Population Studies, 29(I), I587-1596.

Chimininge, V. (20/4). Zion Christian Church. Exploring Religion in Africa IMultiplying Spririt, 15.

Dionne, K. Y., \& Poulin, M. (20I3). Ethnic identity, region and attitudes towards male circumcision in a high HIVprevalence country. Global Public Health, 8(5), 607-618. http://doi.org//0.1080/I744I692.20I3. 790988

Downs, J. A., Fuunay, L. D., Fuunay, M., Mbago, M., Mwakisole, A., Peck, R. N., \& Downs, D. J. (20|3). 'The body we leave behind': a qualitative study of obstacles and opportunities for increasing uptake of male circumcision among Tanzanian Christians. BMJ Open, 3(5), e002802. http://doi.org/10.1 I36/bmjopen-2013002802

Drain, P. K., Halperin, D. T., Hughes, J. P., Klausner, J. D., \& Bailey, R. C. (2006). 
Male circumcision, religion, and infectious diseases: an ecologic analysis of 118 developing countries. BMC Infectious Diseases, 6(I), 172. http://doi.org/I0.1 |86/|47|-2334-6172

Gasasira, R. A., Sarker, M., Tsague, L., Nsanzimana, S., Gwiza, A., Mbabazi, J., ... Mugwaneza, P. (20/2). Determinants of circumcision and willingness to be circumcised by Rwandan men, 2010. BMC Public Health, I2(I), 134. http://doi.org//0.1 |86//47|-2458-I2134

Gray, R., Serwadda, D., Tobian, A. A. R., Chen, M. Z., Makumbi, F., Suntoke, T., ... Wawer, M. J. (2009). Effects of Genital Ulcer Disease and Herpes Simplex Virus Type 2 on the Efficacy of Male Circumcision for HIV Prevention: Analyses from the Rakai Trials. PLoS Med, 6(II), el000I87. http://doi.org/I0.137|/journal.pmed. I0 00187

Keetile, M., \& Rakgoasi, S. (20I4). Male Circumcision; Willingness to undergo Safe Male Circumcision and HIV Risk Behaviors among Men in Botswana. African Population Studies, 28(3), |345-136|.

Khumalo-Sakutukwa, G., Lane, T., vanRooyen, H., Chingono, A., Humphries, H., Timbe, A., ... Morin, S. F. (20/3). Understanding and Addressing SocioCultural Barriers to Medical Male Circumcision in Traditionally NonCircumcising Rural Communities in Sub-Saharan Africa. Culture, Health \& Sexuality, 15(9). http://doi.org//0.1080/|369|058.20|3. 807519
Macintyre, K., Andrinopoulos, K., Moses, N., Bornstein, M., Ochieng, A., Peacock, E., \& Bertrand, J. (20|4). Attitudes, Perceptions and Potential Uptake of Male Circumcision among Older Men in Turkana County, Kenya Using Qualitative Methods. PLOS ONE, 9(5), e83998. http://doi.org//0.137|/journal.pone.00 83998

Mattson, C. L., Bailey, R. C., Muga, R., Poulussen, R., \& Onyango, T. (2005). Acceptability of male circumcision and predictors of circumcision preference among men and women in Nyanza Province, Kenya. AIDS Care, I7(2), 182-194.

http://doi.org//0.1080/09540 | 205 | 233 |32567|

Mavhu, W., Buzdugan, R., Langhaug, L. F., Hatzold, K., Benedikt, C., Sherman, J., ... Cowan, F. M. (20II). Prevalence and factors associated with knowledge of and willingness for male circumcision in rural Zimbabwe. Tropical Medicine \& International Health, 16(5), 589-597. http://doi.org//0.1 I I I/j. I365-

3I56.20II.02744.x

MOHCW. (2009). Zimbabwe Policy Guidelines on Safe and Voluntary Male Circumcision. Ministry of Health and Child Welfare.

Ngalande, R. C., Levy, J., Kapondo, C. P. N., \& Bailey, R. C. (2006). Acceptability of Male Circumcision for Prevention of HIV Infection in Malawi. AIDS and Behavior, 10(4), 377-385. http://doi.org//0.1007/s 1046I-0069076-8

Njeuhmeli, E., Forsythe, S., Reed, J., Opuni, M., Bollinger, L., Heard, N., ... Hankins, C. (20II). Voluntary Medical 
Male Circumcision: Modeling the Impact and Cost of Expanding Male Circumcision for HIV Prevention in Eastern and Southern Africa. PLoS Med, $8(\mathrm{II})$, el00II32. http://doi.org//0.137|/journal.pmed.I0 01132

Parsons, T., \& Shils, E. (195I). Toward a General Theory of Action: Theorectical Foundations for the Social Sciences (Eds). New York: Transaction Publishers.

Plotkin, M., Castor, D., Mziray, H., Küver, J., Mpuya, E., Luvanda, P. J., ... Mahler, H. (20|3). 'Man, what took you so long?' Social and individual factors affecting adult attendance at voluntary medical male circumcision services in Tanzania. Global Health: Science and Practice, I(I), 108-116. http://doi.org//0.9745/GHSP-D-I200037

Rosenstock, I. ., Strecher, V. ., \& Becker, M. . (1994). Preventing AIDS: Theories and Methods of Behavioral Interventions. U.S: Springer US.

Scott, B. ., Weiss, H. A., \& Viljoen, J. . (2005). The acceptability of male circumcision as an HIV intervention among a rural Zulu population, KwaZulu-Natal, South Africa. AIDS Care, I7(3), 304-3।3.

Tarimo, E. A., Francis, J. M., Kakoko, D., Munseri, P., Bakari, M., \& Sandstrom, E. (20I2). The perceptions on male circumcision as a preventive measure against HIV infection and considerations in scaling up of the services: a qualitative study among police officers in Dar es Salaam, Tanzania. BMC Public Health, I2(I), 529. http://doi.org//0.1 I86//47I-2458-I2529

Tarusarira, J., \& Ganiel, G. (20|2). Religion,Secular, Democracy and Conflict Resolution in Zimbabwe. In The Ashagate Research Companion to Religious and Conflict Resolution (pp. 99-177). Ashagate Publishing: Farnham [etc] Ashgate.

Tobian, A. A. R., Gray, R. H., \& Quinn, T. C. (20I0). Male Circumcision for the Prevention of Acquisition and Transmission of Sexually Transmitted Infections. Archives of Pediatrics \& Adolescent Medicine, 164(I), 78-84. http://doi.org//0.1001/archpediatrics.2 009.232

WHO. (20I4). WHO Progress Brief Voluntary medical male circumcision for HIV prevention in priority countries of East and Southern Africa. Geneva, Switzerland: World Health Organisation.

WHO/UNAIDS. (201 I). Progress in scaleup of male circumcision for HIV prevention in Eastern and Southern africa: Focus on service delivery. Geneva, Switzerland.

Zimbabwe National Statistics Agency. (20I2). Census 20/2 National Report. Harare: ZIMSTAT. 